\title{
OECD Ülkelerine Ait Çeşitli Enerji Tüketimleri ve Ekonomik Büyüme Arasındaki İlişkinin Panel Eşbütünleşme Analizi ile İncelenmesi
}

\author{
Investigation of the Relationship between Various Energy Consumption and Economic \\ Growth Belonging to OECD Countries by Panel Cointegration Analysis
}

\author{
Yıldırım Demir' ${ }^{1}$, Çetin Görür ${ }^{2}$ (1)
}

Öz

Ülkelerin gelişmişlik düzeyini gösteren önemli parametrelerden biri de enerji tüketimidir. Genel anlamda sanayi olarak gelişmişlik gösteren ülkelerde daha çok enerji tüketilmektedir. Bu bağlamda enerji ihtiyacı yüksek olan ülkeler dışa bağımlı olmamak için farklı alternatif enerji kaynaklarına yönelmektedirler. Bu çalışmada 36 OECD ülkesine ait çeşitli enerji türleri tüketimi ve ekonomik büyüme arasındaki ilişki Westerlund (2007) panel eşbütünleşme testi ile analiz edilmiştir. Eşbütünleşme testinden önce verilerin heterojenliği test edilmiş, verilere çeşitli yatay kesit bağımlılık testleri uygulanmış ve paneli oluşturan yatay kesitlerin birbirleri ile bağımlılı̆ı incelenmiştir. Ayrıca, CIPS testi kullanılarak da verilerin durağan olup olmadığı belirlenmiştir. LM, LMadj ve CDLM istatistiklerine göre $(p<0.05)$ yatay kesit bağımlılığının olduğu belirlenmiştir. Böylece ikinci kuşak birim kök testleri kullanılmasının uygun olacağına karar verilmiştir. CIPS testine göre değişkenlerin durağan olmadığı belirlenmiştir. Düzeyde durağan olmayan verilerin birinci farkları alınarak verilere tekrar durağanlık analizi uygulanmış ve verilerin durağan hale getirildiği gözlenmiştir. Sonuçlar enerji tüketimi ile ekonomik büyüme arasında eşbütünleşmenin olduğunu göstermektedir. Ayrıca uzun dönemli eşbütünleşme testi sonucunda hidroelektrik ve yenilenebilir enerji tüketimi ile ekonomik büyüme arasında pozitif, termik enerji tüketimi ile ekonomik büyüme arasında ise negatif bir ilişkinin var olduğu belirlenmiştir.

\section{Anahtar Kelimeler}

Ekonomik büyüme, Enerji tüketimi, Eşbütünleşme testi, Panel veri

\begin{abstract}
One of the important parameters showing the development level of the countries is energy consumption. In general terms, in the countries that show developed as industry are consuming more energy. In this context, countries with high energy needs are turning to different alternative energy sources in order not to be dependent on foreign sources. In this study, the relationship between various energy types' consumption and economic growth belonging to 36 OECD countries was analyzed by Westerlund (2007) panel cointegration test. Before Cointegration test, the heterogeneity of the data was tested, various cross-section dependency tests were applied to the data and the dependency of crosssections forming the panel was examined. In addition, it was determined whether the data is stationary by using CIPS test. According to the LM, LMadj and CDLM statistics $(p<0.05)$, cross-sectional dependence was determined. Thus, it was decided that it would be appropriate to use the second generation unit root tests. According to CIPS test, it was
\end{abstract}

1 Sorumlu Yazar: Yıldırım Demir (Dr. Öğr. Üyesi), Van Yüzüncü Yıl Üniversitesi, iktisadi ve İdari Bilimler Fakültesi, Ekonometri Bölümü, Van, Türkiye. E-posta: ydemir@yyu.edu.tr ORCID: 0000-0002-6350-8122

2 Çetin Görür (Doktora Öğrencisi), İnönü Üniversitesi, Sosyal Bilimler Enstitüsü, Ekonometri Bölümü, Malatya, Türkiye. E-posta: gorurcetin@hotmail.com ORCID: 0000-0002-9556-5068

Attf: Demir, Y. ve Gorur, C. (2020). OECD Ülkelerine Ait Çeşitli Enerji Tüketimleri ve Ekonomik Büyüme Arasındaki ilişkinin Panel Eşbütünleşme Analizi ile İncelenmesi. EKOIST Journal of Econometrics and Statistics, 32, 15-33. https://doi.org/10.26650/ekoist.2020.32.0005 
determined that the variables were not stationary. The first differences of the non-stationary data were taken and again the stationary analysis was applied to the data and it was observed that the data were made stationary. The results showed that there is cointegration between energy consumption and economic growth. In addition, as a result of long-term cointegration test, it was determined that there is a positive relationship between hydroelectric and renewable energy consumption and economic growth, and a negative relationship between thermal energy consumption and economic growth.

Keywords

Economic growth, Energy consumption, Cointegration test, Panel data

\section{Extended Summary}

Energy consumption is some of the important parameters showing the development level of the countries. The countries where the energy consumption is high are the countries that have industrial investments and industrial exports in general. Countries with low energy consumption are generally developed in the agriculture and livestock sector. Energy consumption is an important need for countries in the globalizing world. Countries that cannot meet this need meet their energy needs through import and thus become foreign dependent. Countries, which are not rich in underground resources, tend to alternative energy sources instead of meeting their foreign dependent energy needs. For example, renewable energy sources are of great importance day by day and decrease dependence on foreign sources. In this study, the relationship between various energy types' consumption and economic growth belonging to 36 (The Organisation for Economic Co-operation and Development) OECD countries was analyzed by panel cointegration test. The results showed that there is cointegration between energy consumption and economic growth.

The energy need that occurs with globalization is of great importance for the countries every day. Particularly limited underground resources or negatively affecting ecological balance causes countries to turn to different alternative energy sources. The most important of these alternative energy sources are renewable energy sources. In addition, renewable energy based on the use of natural resources in the region where the facility is established reduces energy import costs and increases domestic consumption and investment expenditures by remaining resources within the country.

In panel data analysis, homogeneity is important in determining appropriate unit root and cointegration tests for variables. Therefore, the homogeneity of the slope parameters was investigated using the delta test. In this context, before the cointegration test, the heterogeneity of the data was tested, various cross-sectional dependency tests were applied to the data, and the interdependence of the crosssectional forming the panel was examined.

Data used in experimental analysis; it is divided into three classes: cross-section data, time series data and pooled data. Cross sectional data consists of different 
units of one or more variables and values obtained at a certain time, time series data consists of a unit of variables and values obtained at different times. Mixed data is also a combination of cross sectional data and time series data. Mixed data is called panel data when the same cross sectional unit is followed for a certain period of time.

The aim of this study is to examine the relationship between energy consumption and economic growth of OECD countries with panel cointegration analysis. Accordingly, data on Gross Domestic Product (GDP) of 36 OECD countries, hydroelectric energy, thermal energy and renewable energy consumption are taken from the official website of the World Bank. GDP, which is the biggest indicator of economic growth, was used as economic growth data in the study.

In the study, Westerlund (2007) panel data analysis was applied to the variables using panel cointegration test and thus the relationship between the variables was determined. The dependence of the cross sectional forming the panel with each other was examined with various cross sectional dependency tests. In addition, the CIPS test based on the extended Dickey-Fulle test tried to determine whether the data was stationary. The unit root test was performed separately for two models, constand and consatand+trend, and analyses were performed after making non-stationary series differences, making them stationary for both models.

$\mathrm{H}_{0}$ hypothesis was rejected according to probability values $(\mathrm{p}<0.05)$ for all tests given, thus, it was determined that there is cointegration between GDP and hydroelectric energy consumption, thermal energy consumption and renewable energy consumption. Thus, a long-term relationship between variables was found according to panel cointegration test results.

The long-term cointegration vector of the model whose heterogeneity, crosssectional dependence and cointegration relation has been determined is estimated by the CCE (Common Corrolated Effects) estimator.

The results obtained in this study may be found as follows. It is seen that there is a long-term positive relationship between GDP and hydroelectric energy consumption. A one-unit increase in hydroelectric energy consumption creates an increase of 1.825 in GDP. In addition, it has been determined that the highest contributor to GDP is the type of hydroelectric energy consumption. It is seen that there is a long-term negative relationship between GDP and thermal energy consumption. A one-unit increase in thermal energy consumption creates a 0.465 decrease in GDP. The high cost of thermal energy production can be shown among the reasons for this negative impact. It is seen that there is a long-term positive relationship between GDP and renewable energy consumption. One unit increase in renewable energy consumption creates an increase of 0.529 in GDP. Although its effect on GDP is higher than thermal energy consumption in the long term, it is lower than hydroelectric energy consumption. 


\section{OECD Ülkelerine Ait Çeşitli Enerji Tüketimleri ve Ekonomik Büyüme Arasındaki İlişkinin Panel Eşbütünleşme Analizi ile İncelenmesi}

Küreselleşme ile birlikte meydana gelen enerji ihtiyacı ülkeler için her geçen gün büyük önem arz etmektedir. Özellikle yeraltı kaynaklarının sınırlı olması ya da ekolojik dengeyi olumsuz etkilemesi ülkelerin farklı alternatif enerji kaynaklarına yönelmelerine sebep olmaktadır. Bu alternatif enerji kaynaklarının en önemlisi de yenilenebilir enerji kaynaklarıdır. Ayrıca tesisin kurulduğu bölgedeki doğal kaynakların kullanımına dayanan yenilenebilir enerji, enerji ithalat maliyetini düşürmekte ve kaynakların ülke içerisinde kalarak yurtiçi tüketim ve yatırım harcamalarının artmasını sağlamaktadır (Özşahin, Mucuk ve Gerçeker, 2016). Rekabet açısından büyük bir ekonomik güce sahip olan enerji, bu yönüyle büyük bir önem arz etmektedir. Böylece ülkeler kendi enerji ihtiyaçlarını gidermek için çalışmalar yürütmektedir.

Gelişmemiş ya da gelişmekte olan ülkeler enerji ihtiyaçlarını genel anlamda ithal ederek gidermektedir. Bu da ekonomik olarak kalkınmayı yavaşlatmaktadır. Yeraltı kaynakları (petrol, doğalgaz vb.) bakımından zengin olan ülkeler bu kaynakları ihraç ederek ekonomik olarak kalkınma sağlamaktadır. IEA (International Energy Agency) tarafindan yapılan bir araştırmada, bazı gelişmekte olan ülkelerde üretim fonksiyonuna enerji dâhil edilmiş ve ekonomik kalkınma açısından ara aşamada bulunan bu ülkelerde, enerjinin ekonomik büyümeye katkısının büyük olduğu ve dolayısıyla ekonomik kalkınmada önemli bir rolünün bulunduğu sonucuna varılmıştır (Ertuğrul, 2011).

Gelişmekte olan ülkelerdeki hızlı büyüme nedeniyle enerji tüketim yoğunluğu yüksek düzeyde gerçekleşirken, gelişmiş ülkelerde büyüme hızındaki yavaşlama nedeniyle enerji tüketim yoğunluğu da düşük düzeyde gerçekleşmektedir (Ağaçbiçer, 2010). Bu nedenle, elektrik enerjisi tüketiminin ekonomik büyümeye pozitif yönde etki ettiği söylenebilir (Karakaş ve Balcı İzgi, 2018).

Deneysel analizlerde kullanılan veriler; yatay kesit verileri (cross-section data), zaman serisi verileri (time series data) ve karma veriler (pooled data) olmak üzere üç sınıfa ayrılmaktadır. Yatay kesit verileri bir veya daha fazla değişkenin farklı birimlerinden ve belli bir zamanda elde edilen değerlerden, zaman serisi verileri ise değişkenlerin bir biriminden ve farklı zamanlarda elde edilen değerlerden meydana gelmektedir. Karma veriler de yatay kesit verileri ile zaman serisi verilerinin birleşiminden oluşmaktadır. Belirli bir zaman döneminde aynı yatay kesit birimi izlenmesi durumda karma veriler, panel veri (panel data) olarak adlandırılmaktadır (Das, 2019; Gujarati, 2003). Yatay kesit verileri, sadece bir döneme göre birçok birim ile ilgili bilgi verirken; zaman serisi verileri ise dönemlere göre sadece bir birim ile ilgili bilgi vermektedir. Böylece, hem dönemler hem de birimler ile ilgili bilgiler elde edilmek isteniliyorsa, panel verilerin kullanılması daha doğru olacaktır (Yerdelen Tatoğlu, 2013). Zira panel verilerin hem kesit hem de zaman boyutu bulunmaktadır. 
Panel veri; birey, hane halkı, şirketler, ülkeler vb. birimlere ait yatay kesitlerin zaman içinde tekrarlanan gözlemlerinden oluşmaktadır (Wooldridge, 2002). Veri setine göre panel veriler dengeli (balanced) ve dengesiz (unbalanced) olmak üzere iki kategoriye ayrılmaktadır. Her bir birim tüm zamanlar boyunca gözlenmiş ise veri seti kesitler arasında farklılık göstermeyecek şekilde eşit uzunlukta olacağından bu tür veri setine dengeli panel; bazı birimler için bazı zamanlar kayıp ise kesitler arasında farklılık olacağından bu tür verilere de dengesiz panel adı verilmektedir. Panel veri analizi, zaman serisi ve kesitlerin bir araya getirilmesi ile oluştuğu için zaman serisine ait özellikleri ve sorunları da taşımaktadır (İşleyen, 2019). Panel veriler, yatay kesit ve zaman serisi verilerini birlikte ele alması nedeniyle verileri hem nicel hem de nitel olarak olumlu etkilemektedir (Gujarati, 2003).

Panel veri modelleri yardımıyla, iktisadi değişkenler arasında nedensellik ilişkileri kurulabilmektedir. Dolayısıyla, panel veri analizi ile ekonomik ilişkiler tahmin edilebilmektedir. Panel veri analizinde genel olarak üç amaç hedeflenmektedir. Bunlar, her bir birimin zaman boyunca değişkenliğini yani birimler arası değişkenliği tanımlamak, zaman boyunca sabit veya değişebilen cinsten olan bazı değişkenleri diğer bazı değişkenler bakımından açıklamak, ilgili değişken açısından her bir birim hakkında tahmin yapmak şeklinde sıralanabilir (Altunkaynak, 2007).

Bu çalışmanın amacı, OECD ülkelerine ait enerji tüketimleri ile ekonomik büyüme arasındaki ilişkinin panel eşbütünleşme analizi ile incelenmesidir. Bu doğrultuda, 36 OECD ülkesine ait Gayri Safi Yurtiçi Hasıla (GSYİH), hidroelektrik enerji, termik enerji ve yenilenebilir enerji tüketimine ait veriler dünya bankasının resmi web adresinden alınmıştır. Ekonomik büyümenin en büyük göstergesi olan GSYİH çalışmada ekonomik büyüme verisi olarak kullanılmıştır.

Bu çalışmanın önemi, OECD’nin temel amaçlarından biri olan ekonomik kalkınma için enerji tüketimleri ile GSYİH arasında eşbütünleşmenin var olup olmadığını incelemektir. Ayrıca OECD’nin çevre ve doğa politikaları doğrultusunda enerji tüketim türlerini ele alıp bu tüketimlerin ne denli ve hangi yönlü GSYİH'ya katk1 sağladığını analiz etmek bu çalışmayı önemli kılmaktadır. Bu bağlamda çalışmanın literatüre katkı sağlayacağı düşünülmektedir. OECD ülkelerinde GSYİH ile enerji tüketim türleri arasında eşbütünleşmenin olup olmadığı çalışmanın hipotezleridir.

\section{Materyal ve Yöntem}

Araştırma materyali, 1999-2018 yıllarını kapsayan 36 OECD ülkesine ait yıllık GSYİH oran1, hidroelektrik enerji, termik enerji ve yenilenebilir enerji tüketiminin toplam tüketim içerisindeki yıllık tüketim oranı verilerinden oluşmaktadır. Veriler dünya bankasının resmi web adresinden alınmış (IBRD IDA, 2020) ve STATA 15 istatistik paket programı ile analiz edilmiştir. 
Çalışmada, Westerlund (2007) panel eşbütünleşme testi kullanılarak değişkenlere panel veri analizi uygulanmış ve böylece değişkenler arasındaki ilişki belirlenmiştir. Çeşitli yatay kesit bağımlılık testleri ile paneli oluşturan yatay kesitlerin birbirleri ile bağımlılığ 1 incelenmiştir. Ayrıca, genişletilmiş Dickey-Fulle testine dayanan CIPS testi kullanılarak da verilerin durağan olup olmadığı belirlenmeye çalışılmıştır.

\section{Heterojenlik Testi}

Panel veri analizinde değişkenler için uygun birim kök ve eşbütünleşme testlerinin belirlenmesinde, homojenlik önemlidir. $\mathrm{Bu}$ nedenle, delta testi kullanılarak eğim parametrelerinin homojenliği araştırılmıştır. Delta test istatistiği eşitlik (1) ile verilmiştir (Pesaran, 2015)

$$
\tilde{\Delta}=\sqrt{N}\left(\frac{N^{-1} \tilde{S}-k}{\sqrt{2 k}}\right)
$$

Eşitlik (1)'de $\tilde{S}$, düzeltilmiş Swamy istatistiği olup N'nin sabit ve T'nin sonsuz olduğu durumda $H_{0}$ hipotezi altında asimptotik olarak $k(N-1)$ serbestlik dereceli Ki-kare dağılımına sahiptir. Eğim parametrelerinin homojenliğini gösteren sıfır hipotez altında, hata terimleri normal dağılırken, Delta test istatistiği standart normal dağılıma yaklaşmaktadır. Küçük örnekler için eşitlik (2)'de verilen düzeltilmiş delta test istatistiği geliştirilmiştir.

$$
\tilde{\Delta}_{a d j}=\sqrt{N}\left(\frac{N^{-1} \tilde{S}-E\left(\tilde{Z}_{i T}\right)}{\sqrt{\operatorname{Var}\left(\tilde{Z}_{i T}\right)}}\right)
$$

$\tilde{Z}_{i T}$ sınırlı ortalama ve varyansa sahip bağımsız rastgele değişkenlerdir. $E\left(\tilde{Z}_{i T}\right)$ ve $\operatorname{Var}\left(\tilde{Z}_{i T}\right)$ sirasıyla $k$ ve $2 k(T-k-1) / T+1$ 'i ifade etmektedir. Homojenlik için hipotezler,

$\mathrm{H}_{0}$ : Eğim katsayısı homojendir.

$\mathrm{H}_{1}$ : Eğim katsayısı homojen değildir, şeklinde kurulmaktadır.

Hipotez testi sonucunda, eğim katsayılarının homojen olduğu belirlenirse yatay kesit birimlerinin değerlendirilmesi için $P_{a}$ ve $P_{t}$ panel test istatistikleri kullanılmaktadır. Ancak, eğim katsayısının homojen olmadığı belirlendiği durumda ise grup test istatistikleri olan $G_{a}$ ve $G_{t}$ test istatistikleri kullanılmaktadir (Aytun ve Akin, 2014).

\section{Yatay Kesit Bağımlılık Testi}

Panel veri analizinde yatay kesiti oluşturan birimler arasında karşılıklı etkileşimler olabilmektedir. Uluslararası karşılıklı ekonomik ilişkilerin gelişmesi ülkelerin birbirleri arasındaki etkileşimini artırmaktadır. Bu durum yatay kesit bağımlılığı olarak 
adlandırılmaktadır. Paneli oluşturan herhangi bir ülkeye gelen iktisadi şokun yine paneli oluşturan diğer ülkeleri etkilemesi yatay kesit bağımlılığı olarak düşünülebilir. Ampirik analizlerde yatay kesit bağımlılı̆̆ dayalı regresyonlardan elde edilen katsayılar sapmalı ve tutarsız olacağından analizler sağlıklı sonuçlar vermemektedir. Bu nedenle öncelikle değişkenler arasında yatay kesit bağımlılığının olup olmadığı araştırılmaktır. Böylece, birim kök testlerinden önce yatay kesit bağımlılık testleri ile zaman serilerinde tutarsızlık ve sapmalar olup olmadığı belirlenmektedir (Menyah, Nazlıoğlu ve Wolde-Rufael, 2014). Yatay kesit bağımlılığı için çeşitli testler geliştirilmiştir. Gözlem sayısı sabit ve yatay kesit boyutu sonsuzken paneldeki birimler arasındaki yatay kesit bağımlılığını test etmek için $L M$ (Lagrange Multiplier) testi uygulanabilmekte ve test istatistiği eşitlik (3) ile hesaplanmaktadir.

$$
L M=T \sum_{i=1}^{N-1} \sum_{j=i+1}^{N} \hat{\rho}_{i j}^{2}
$$

Eşitlik (3)'de $\hat{\rho}$ en küçük kareler hata terimlerinin ardışık korelasyonunun örneklem tahmini, $T$ yatay kesit boyutu ve $N$ gözlem sayısıdır. $L M$ testinde, sıfır hipotezi yatay kesitlerin birbirinden bağımsız olduğunu göstermekte ve $N$ sabitken $T$ sonsuza gittiğinde test asimptotik olarak N(N-1)/2 serbestlik derecesine sahip kikare dağılımına yakınsamaktadır (Pesaran, 2015; Hsiao, 2014). Eşitlik (3)'de T'nin boyutunun $N$ 'den büyük olduğu varsayılmaktadır. Aksi durumda, bu testin kullanımı uygun olmamaktadır. Bu nedenle, $C D_{L M}$ testi geliştirmiş ve bu test, her bir alternatif içerisinde $T$ yatay kesit boyutu ve $N$ gözlem sayısının sonsuza gittiği durumda kullanılmaktadır (Pesaran, 2007). $C D_{L M}$ test istatistiği eşitlik (4) ile verilmiştir.

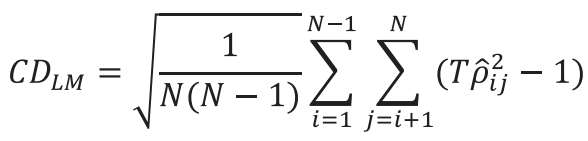

$C D_{L M}$ testine göre hem kesit sayısı hem de gözlem sayısı sonsuza gittiği için panelde yatay kesit bağımlılığının olmadığı varsayılmaktadır. Ancak, gözlem sayısı kesit sayısından büyük $(N>T)$ olduğu durumlarda $C D_{L M}$ testinde önemli bozulmalar görülmektedir. Bu sorunun çözümü için $L M_{a d j}$ (sapması düzeltilmiş) test istatistiği önerilmektedir. $L M_{a d j}$ testi büyük $N$ ve sonlu $T$ panellerindeki sapmaları düzeltmekte ve test istatistiği eşitlik (5) ile hesaplanmaktadır.

$$
L M_{a d j}=\sqrt{\frac{2}{N(N-1)} \sum_{i=1}^{N-1} \sum_{j=i+1}^{N} \frac{(T-k) \hat{\rho}_{i j}^{2}-\mu_{i j}}{\sqrt{w_{i j}^{2}}}}
$$


Burada, $\mu_{i j}=E\left[(T-k) \hat{\rho}_{i j}^{2}\right], w_{i j}^{2}=\operatorname{Var}\left[(T-k) \hat{\rho}_{i j}^{2}\right], \quad$ ve $k$ ise açıklayıcı değişken $\left(x_{i t}\right)$ sayısını göstermektedir. Asimptotik olarak test istatistiği ortalaması 0 ve varyansı 1 olan standart normal dağılıma uyum göstermektedir (Hsiao, 2014). Sonuç olarak, yatay kesit bağımlılı̆̆ı için sıfır hipotezi ve alternatif hipotez,

$\mathrm{H}_{0}$ : Yatay kesit bağımlılığı yoktur.

$\mathrm{H}_{1}$ : Yatay kesit bağımlılı̆̆ vardır.

şeklinde kurulmaktadır. Verilen $\alpha$ anlamlılık düzeyinde, $\mathrm{H}_{0}$ 'n kabul edilmesi durumda birinci kuşak birim kök testleri, $\mathrm{H}_{0}$ 'n reddedilmesi durumda ise ikinci kuşak birim kök testleri kullanılmaktadır. Ayrıca seriye gelen bir şok karşısında, paneli oluşturan yatay kesit birimlerinin birbirinden hiçbir zaman etkilenmediği varsayımı gerçeği yansıtmadığından, etkin bir tahmin için yatay kesit bağımlılığını dikkate alan ikinci kuşak birim kök testlerinin uygulanması daha sağlıklı sonuçlar vermektedir (Erataş ve Başçı Nur, 2013). Bu nedenle çalışmada, serilerin durağan olup olmadığının belirlenmesi için ikinci kuşak birim kök testlerinden CIPS testi kullanılmıştır.

\section{Panel Birim Kök Testi}

Zaman serisi çalışmalarında durağan, stokastik süreçlere olan ilgi giderek artmaktadır. Hesaplanan kovaryans değerinin gerçek zamanına değil, sadece iki zaman periyodu arasındaki mesafeye veya gecikmeye bağlı olan iki zaman periyodu arasındaki kovaryans değeri ve zaman içinde ortalama ve varyans sistematik olarak değişmiyorsa, genel olarak stokastik bir süreç "durağan" olarak adlandırılmaktadır (Gujarati, 2003). Daha sade bir ifadeyle, stokastik süreçlerin şartlı olasılık dağılımları zaman içerisinde değişmiyorsa bu serilere durağan seriler denilir (İşleyen, Altun ve Görür, 2017).

Serilerin durağan olmaması sorunu, zaman serileriyle çalışılırken sıklıkla karşılaşılan bir durumdur. Zaman serilerinin durağan olması çok önemlidir. Zira durağan olmayan bir veri seti kullanılarak kurulan bir modelde değişkenler arasındaki ilişki tahmin edildiğinde, değişkenler arasında istatistiki olarak anlamlı bir ilişki olmamasına rağmen genellikle gerçekte var olmayan istatistiki bir ilişki görülebilir. $\mathrm{Bu}$ durum, zaman serilerinde sahte veya saçma regresyon olarak adlandırılan soruna neden olmaktadır (Sevüktekin ve Nargeleçekenler, 2005; Eygü, 2018). Sahte regresyon olaylarını engellemede durağanlık testleri önem arz etmektedir. Gerçekleştirilen durağanlık testleri ile durağan olmayan seriler belirlenirse, fark alma işlemi ile bu seriler durağan hale getirilmektedir.

Panel veri modelleri bünyesinde zaman serisi bulunması nedeniyle, panel verilerin durağan olup olmadığı birim kök testleriyle kontrol edilmektedir. Birim kök testleri, genel olarak birinci ve ikinci kuşak olmak üzere ikiye ayrılmaktadır. Birinci kuşak testler ile bireysel ve ikinci kuşak testler ile de ortak birim kök varlığı test edilmektedir. 
Her iki kuşakta da birçok farklı birim kök testi bulunmaktadır (Das, 2019). Ancak, bu çalışmada panel veri değişkenlerinin durağan olup olmadığını test etmek amacıyla, veri yapısı göz önüne alındığında ikinci kuşak birim kök testlerinde biri olan CIPS (CrossSectionally Augmented IPS) testi kullanılmıştır.

Tau $(\tau)$ test istatistiği olarak bilinen DF (Dickey-Fuller) panel birim kök testi, verilen modelde $p=0$ hipotezinin reddine (zaman serileri durağandır) dayanmaktadır. $\mathrm{H}_{\mathrm{o}}$ reddedilmediğinde birim kökün varlığına ve dolayısıyla, serinin durağan olmadığı sonucuna varılmaktadır. Bir panel veri seti, hem stokastik hem de deterministik eğilim gösteren, yani hem durağan hem de durağan olmayan zaman serisi barındırıyorsa birim kök için hipotezler,

$\mathrm{H}_{0}: p=0$ (Seride birim kök vardır veya seri durağan değildir)

$\mathrm{H}_{1}: p<0$ (Seride birim kök yoktur veya seri durağandır) şeklinde kurulmaktadır.

İlkin Pesaran (2004) tarafından, serilere ait hatalarla ilişkili yatay kesit bağımlılığı altında birim kökleri test etmek amacıyla basit bir yöntem ve daha sonraki yıllarda DF yerine Genişletilmiş DF (Augmented Dickey-Fuller, ADF) testi önerilmiştir (Baltagi, 2005). Takip eden yıllarda ise Pesaran (2007) tarafindan ADF modeline dayanan, yatay kesiti genişletilmiş Dickey-Fuller (CADF) istatistiği önerilmiştir (Croissant ve Millo, 2019).

CADF modelinde, bireysel serilerin gecikmeli düzeyleri ve birinci dereceden farkları alınarak yatay kesit ortalaması ile ADF regresyon modeli genişletilmekte ve böylece, birimler arasındaki bağımlılı̆̆ın yok edildiği ileri sürülmektedir. CADF regresyon modeli eşitlik (6)'da verilmiştir.

$$
\Delta y_{i t}=a_{i}+b_{i} y_{i, t-1}+c_{i} \bar{y}_{t-1}+d_{i} \Delta \bar{y}_{t}+e_{i t} \quad i=1, \ldots, N ; t=1, \ldots, T
$$

Burada, $t$ zaman veya genel eğilim değişkeni olup $e_{i t}$ bireye özel (bireyin kendine özgü) hatayı, $a_{\mathrm{i}}, b_{\mathrm{i}}$ ve $c_{\mathrm{i}}$ sabit etki katsayılarını ve $y_{\mathrm{i}, 0}$ ölçülebilir bir ortalama ve varyans ile belirli bir yoğunluk fonksiyonuna sahip başlangıç değerlerini göstermektedir. Ayrıca $\bar{y}_{t}$ tüm $\mathrm{N}$ gözlemlerinin $t$ zamanındaki ortalaması olup $\bar{y}_{t}=\frac{\sum_{i=1}^{N} y_{i t}}{N}$ eşitliği ile ve $\Delta \bar{y}_{t}=\frac{\sum_{i=1}^{N} \Delta y_{i t}}{N}$ eşitliği ile hesaplanmaktadır. Her kesit için ayrı ayrı hesaplanan CADF değerlerinin aritmetik ortalaması alınarak panelde birim kök olup olmadığ1 hakkında karar verilmektedir (Das, 2019). Bu nedenle, CADF modelinin aritmetik ortalaması olan yatay kesite özgü geliştirilmiş IPS (CIPS) test istatistiği kullanılmakta ve test için hipotezler,

$\mathrm{H}_{0}: p_{i}=0$ (Serideki tüm kesitlerde birim kök vardır)

$\mathrm{H}_{1}: p_{i}<0$ (Serideki en az bir kesitte birim kök yoktur) şeklinde kurulurken, test istatistiği eşitlik (7) ile hesaplanmaktadır. 


$$
C I P S=\frac{1}{N} \sum_{i=1}^{N} C A D F_{i}
$$

CIPS testi panelin geneline dair durağanlık analizi yapmakta olup test istatistiklerinin ve kritik değerlerinin karşılaştırılmasında bunların mutlak değerleri kullanılmaktadır (Pesaran, 2007).

Eşitlik (6)'daki model birinci dereceden hata süreci için verilmiş olsa da eşitlik (8)'deki yaklaşım ile daha yüksek dereceden süreçler için yeniden düzenlenebilir.

$$
\Delta y_{i t}=a_{i}+b_{i} y_{i, t-1}+c_{i} \bar{y}_{t-1}+\sum_{j=0}^{p} d_{i j} \Delta \bar{y}_{t-j}+\sum_{j=1}^{p} \delta_{i j} \Delta y_{i, t-j}+e_{i t} \quad i=1, \ldots, N ; \quad t=1, \ldots, T
$$

Burada bireysel CADF istatistikleri, $p$. dereceden yatay kesit/zaman serisi artırılmış regresyonundan $b_{i}$ 'nin en küçük kareler yöntemi ile tahmin edilen $\mathrm{t}$ oranı ile verilmektedir (Baltagi, 2005; Das, 2019).

Birim kök testlerinin uygulanması sürecinde, uygun gecikme düzeyinin belirlenmesi en önemli sorunlardan birisi olarak karşımıza çıkmaktadır. Gecikme düzeyini belirlemede genellikle Akaike (AIC) ve Schwarz (SCI) bilgi kriteri kullanılmaktadır (Göral, 2015).

\section{Panel Eşbüiünleşme Testi}

Ampirik çalışmalar neticesinde makroekonomi zaman serilerinin büyük bir kısmının durağan olmayan serilerden oluştuğu belirlenmiştir. Durağan olmayan bu serilerin birim kök içermesi sahte regresyona neden olmaktadır. Sahte regresyon sorununu çözmek için durağan olmayan bu seriler yerine bu serilerin farkları alınarak bu farkların regresyona tabi tutulması önerilen birçok farklı yöntemden birisidir. Ancak, fark alma yönteminde de uzun dönem denge için önemli olan bazı bilgilerin kaybedilmesi gibi bir sorun baş gösterebilmektedir. Zira serilerin birinci farklarının alınması ile yapılan analizler, bu seriler arasında var olan uzun dönemli ilişkinin ortadan kaldırılmasına neden olabilmektedir. Bu sorunun ortadan kaldırılması için de eşbütünleşme analizi önerilmektedir. Eşbütünleşme, değişkenler arasında uzun dönem denge ilişkisi olup olmadığını test eden ve söz konusu ilişkiyi doğrudan tahmin etmeye olanak tanıyan bir yöntem olarak tanımlanmaktadır (Pedroni, 2004). Eşbütünleşme testleri için hipotezler,

\section{$\mathrm{H}_{0}$ : Değişkenler arasında eş bütünleşme yoktur}

$\mathrm{H}_{1}$ : Değişkenler arasında eş bütünleşme vardır, şeklinde kurulmaktadır.

Hata düzeltme modeline dayanan ve panel eşbütünleşme testi olan Westerlund (2007), panel verilerle çalışılırken iki veya daha fazla değişken arasındaki eşbütünleşme ilişkisini sınamak amacıyla kullanılmaktadır. Test temelde, her birimin 
kendi hata düzeltmesi olup olmadığına karar vermesi yöntemiyle eşbütünleşme varlığını sınamaktadır (Yerdelen Tatoğlu, 2017). Bu test Banerjee, Dolado ve Mestre. (1998) tarafından, zaman serileri için geliştirilen eşbütünleşme testinin panel veri için genişletilmiş halidir. Testin önemli varsayımı, serilerin aynı derecede durağan olmalarıdır. Westerlund geliştirdiği eşbütünleşme testi,

$$
Z(M)=\frac{1}{N} \sum_{i=1}^{N} \sum_{j=1}^{M_{i}+1} \sum_{t=T_{i j-1}+1}^{T_{i j}} \frac{S_{i t}^{2}}{\left(T_{i j}-T_{i j-1}\right)^{2} \hat{\sigma}_{i}^{2}}
$$

olarak verilmiştir. Eşitlik (9)'da; $T$ zaman boyutu, $N$ paneldeki birim sayısı, $M$ değişken sayısıdır. Panel $N$ tane farklı bireyden oluştuğunda, her biri $M$ değişkene sahip $N$ tane farklı denklem oluşmaktadır (Altunkaynak, 2007).

Test istatistiklerinin oluşturulması amacıyla Westerlund (2007) tarafından verilen alternatif yaklaşımlardan biri de eşitlik (10)'da verilmiştir.

$$
\Delta y_{i t}=\delta_{i}^{\prime} d_{t}+\alpha_{i} y_{i, t-j}+\lambda_{i}^{\prime} x_{i, t-1}+\sum_{j=0}^{p_{i}} \gamma_{i j} \Delta x_{i, t-j}+\sum_{j=1}^{p_{i}} \alpha_{i j} \Delta y_{i, t-j}+e_{i t}
$$

Burada $d_{t}=(1, t)^{\prime}$ deterministik bileşenler ve $\delta_{i}=\left(\delta_{1 i}, \delta_{2 i}\right)^{\prime}$ parametrelerin ilişkili vektörüdür. Hata düzeltme parametresi olan $a_{i}$ en küçük kareler yöntemi ile tahmin edilmektedir. Westerlund (2007) tarafından, eşitlik (10)'da verilen $a_{i}$ 'nin en küçük kareler tahminine ve onun $t$ oranına dayanan dört test istatistiği sunulmuştur.

Grup ortalama test istatistikleri olan $G_{\alpha}$ ve $G_{\tau}$ değerlerinin hesaplanmasında her bir kesit için hata düzeltme modelinin tahmin edilmesi gerekmektedir. Grup ortalama test istatistikleri,

$$
G_{\alpha}=\frac{1}{N} \sum_{i=1}^{N} \frac{T \hat{\alpha}_{i}}{\hat{\alpha}_{i}(1)} \quad G_{\tau}=\frac{1}{N} \sum_{i=1}^{N} \frac{\hat{\alpha}_{i}}{S E\left(\hat{\alpha}_{i}\right)}
$$

olarak ve panelin bir bütün olarak analiz edilmesi için Westerlund (2007) eşbütünleşme test istatistikleri ise,

$$
P_{\alpha}=T \hat{\alpha} \quad P_{\tau}=\frac{\hat{\alpha}}{S E(\hat{\alpha})}
$$

olarak verilmiştir. $a_{i}$ 'in yarı parametrik karnel tahmincisi $\hat{\alpha}_{i}$ ve $\hat{\alpha}_{i}$ 'nin standart hatası ise $S E\left(\hat{\alpha}_{i}\right)$ ile gösterilmiştir.

Bootstrap Yöntemi; istatistiksel tahmin işleminin defalarca tekrar edilmesiyle oluşan itertif bir süreçtir (Shao, 1995). Bu yöntem, EKK varsayımlarının sağlanamaması durumunda bir düzeltme işlemi olarak da kullanılmaktadır. Güven 
aralıklarının oluşturulması, hata tahminlerinin minimize edilmesi, standart sapmaların küçültülmesi ve parametre tahminlerinin daha da güvenilir kılınması Bootstrapın amaçlarındandır (Efron ve Tibshirani, 1993).

Heterojenlik, yatay kesit bağımlılığı ve eşbütünleşme ilişkisi belirlenmiş olan modele ait uzun dönem eşbütünleşme vektörü CCE (Common Corrolated Effects) tahmincisi ile tahmin edilmektedir. Uzun dönem eşbütünleşme katsayılarının tahmininde CCE tahmincisi $N, T \rightarrow \infty$ olduğu zaman tutarlı olup asimptotik bir dağılım göstermektedir (Pesaran, 2004). CCE modeli, panel veri analizinde her bir yatay kesit birimi için tahmin edilen regresyon katsayılarının tek tek elde edilmesini sağlamaktadır (Erataş ve Başçı Nur, 2013). Uzun dönem eşbütünleşme Pesaran test modeli eşitlik (11)'de verilmiştir.

$$
y_{i t}=\delta_{i}^{\prime} d_{t}+\lambda_{i}^{\prime} x_{i, t}++e_{i t}
$$

Bu modelde, yatay kesit bağımlılığını dikkate alan açıklayıcı değişkenlere ait uzun dönem regresyon katsayılarının tahmininde CCEMG (Common Correlated Effects Mean Group) ve CCEP (Common Correlated Effects Pooled) olmak üzere iki farklı alternatif tahminci bulunmaktadır. CCEMG yaklaşımında açıklayııı değişkenlere ait uzun dönem parametreler, her bir yatay kesit için bulunan katsayıların aritmetik ortalaması alınarak hesaplanmaktadır. Her bir yatay kesit birimi için CCE tahmincisi $\hat{\beta}_{C C E, i}\left(\hat{\beta}_{C C E, i}=\left(X_{i}^{\prime} \bar{M}_{w} X_{i}\right)^{-1} X_{i}^{\prime} \bar{M}_{w} y_{i .}\right)$ olmak üzere panel eşbütünleşme katsayısı CCEMG yaklaşımı kullanılarak eşitlik (12) ve CCEP yaklaşımı kullanılarak da eşitlik (13) ile hesaplanmaktadır (Pesaran, 2015; Erataş ve Başçı Nur, 2013).

$$
\begin{aligned}
& \hat{\beta}_{C C E M G}=N^{-1} \sum_{i: 1}^{N} \hat{\beta}_{C C E, i} \\
& \hat{\beta}_{C C E P}=\left(\sum_{i: 1}^{N} w_{i} X_{i}^{\prime} \bar{M}_{w} X_{i}\right)^{-1} \sum_{i: 1}^{N} w_{i} X_{i}^{\prime} \bar{M}_{w} y_{i}
\end{aligned}
$$

\section{Araştırma Bulguları}

Panel veri analizinde kullanılacak değişkenlerin eğim katsayılarına ait homojenlik test sonuçları Tablo 1.'de verilmiştir.

Tablo 1

Homojenlik test istatistik ve olasılık değerleri

\begin{tabular}{lcc}
\hline Değişkenler & Test istatistiği & p-değeri \\
\hline GSYİH & -1.037 & 0.03 \\
Hidroelektrik Enerji Tüketimi & -0.893 & 0.04 \\
Termik Enerji Tüketimi & 0.103 & 0.02 \\
Yenilenebilir Enerji Tüketimi & 1.302 & 0.73 \\
\hline
\end{tabular}

$(\mathrm{p}<0.05)$ 
Tablo 1'de, GSYİH, Hidroelektrik Enerji Tüketimi ve Termik Enerji Tüketimi değişkenleri için eğim katsayılarının heterojen $(\mathrm{p} \leq 0.05)$ olduğu, Yenilenebilir Enerji Tüketimi değişkeni için ise eğim katsayısının homojen $(p \geq 0.05)$ olduğu görülmektedir. Dolayısıyla Westerlund eşbütünleşme test sonuçlarında dikkate alınacak test istatistikleri bu iki durum için farklılaşmaktadır. Bu nedenle, GSYİH ile hidroelektrik ve termik enerji tüketimi arasında bir eşbütünleşme ilişkisi olup olmadığını belirlemek için $P_{a}$ ve $P_{T}$; GSYİH ile yenilenebilir enerji tüketimi arasında bir eşbütünleşme ilişkisi olup olmadığını belirlemek için ise $G_{a}$ ve $G_{\tau}$ test istatistikleri kullanılmıştır.

Panel veri analizinde kullanılacak verilerin durağanlığını sınamak için hangi kuşak birim kök testinin uygulanması gerektiğini belirlemek amacıyla yatay kesit bağımlılık testleri uygulanmış ve test istatistik sonuçları Tablo 2'de verilmiştir.

Tablo 2

Yatay kesit bağımlılık test sonuçları

\begin{tabular}{lcc}
\hline Test & İstatistik & p-değer \\
\hline LM & 4151 & 0.001 \\
$\mathrm{LM}_{\text {adj }}$ & 210.7 & 0.001 \\
$\mathrm{CD}_{\text {LM }}$ & 59.56 & 0.001 \\
\hline
\end{tabular}

$(\mathrm{p}<0.05)$

Tablo 2 incelendiğinde, tabloda $L M, L_{\text {adj }}$ ve $C_{L M}$ test istatistikleri ve olasılık değerleri verilmiştir. Verilen olasılık değerlerine göre $(\mathrm{p}<0.05)$ yatay kesit bağımlılığının yokluğu reddedilmiştir. Böylece $\alpha=0.05$ anlamlılık düzeyinde yatay kesit bağlamlılı̆̆ının olduğu söylenebilir. Bu durumda test analizi için ikinci kuşak birim kök testleri kullanılmasının uygun olacağına karar verilmiştir. Bu nedenle, serilerin durağanlığını test etmek için ikinci kuşak birim kök testlerinden biri olan CIPS testi uygulanmış ve bu test ile panelin geneli için durağanlık analizi yapılmıştır.

Çalışmada, CIPS testi sabit ve sabit+trendli modeller için uygulanmış ve düzeyde durağan olmayan verilerin birinci farkları alınarak veriler durağan hale getirilmiştir. Tablo 2 incelendiğinde, hem I(0) (düzeyde) hem de I(1) (verilerin birinci farkları) için 0.05 anlamlılık düzeyinde sabit ve sabit+terndli modellere ait test istatistikleri, p-değerleri ve kritik değerler verilmiştir. 
Tablo 3

Değişkenler için sabit ve sabit+trendli model birim kök test istatistikleri ve olasılık değerleri

\begin{tabular}{|c|c|c|c|c|c|c|c|c|}
\hline \multirow{3}{*}{ Değişkenler } & \multicolumn{4}{|c|}{$\mathrm{I}(\mathbf{0})$} & \multicolumn{4}{|c|}{$\mathrm{I}(1)$} \\
\hline & \multicolumn{2}{|c|}{ *Sabit } & \multicolumn{2}{|c|}{$* *$ Sabit+Trendli } & \multicolumn{2}{|c|}{ *Sabit } & \multirow[b]{2}{*}{ t-bar } & \multirow[b]{2}{*}{ p-değeri } \\
\hline & t-bar & p-değeri & t-bar & p-değeri & t-bar & p-değeri & & \\
\hline GSYİH & -2.601 & 0.613 & -3.190 & 0.312 & -2.710 & 0.001 & -3.702 & 0.024 \\
\hline $\begin{array}{l}\text { Hidroelektrik } \\
\text { Enerji } \\
\text { Tüketimi }\end{array}$ & -2.513 & 0.409 & -3.003 & 0.237 & -2.872 & 0.006 & -3.509 & 0.010 \\
\hline $\begin{array}{l}\text { Termik Enerji } \\
\text { Tüketimi }\end{array}$ & -2.507 & 0.207 & -3.290 & 0.328 & -2.732 & 0.003 & -3.487 & 0.009 \\
\hline $\begin{array}{l}\text { Yenilenebilir } \\
\text { Enerji } \\
\text { Tüketimi }\end{array}$ & -2.541 & 0.497 & -3.017 & 0.241 & -2.816 & 0.005 & -3.537 & 0.017 \\
\hline
\end{tabular}

Not: Maksimum gecikme uzunluğu 2 olarak alınıp ve Schwarz bilgi kriteri dikkate alınarak optimal gecikme uzunluğu belirlenmiş, sabit model için Cv5: $-2.65^{*}$, sabit+trendli model için Cv5: $-3.45^{* *}$

Birim kök varlığı ilk önce I(0) için sabit ve sabit+trendli modeller gözönüne alınarak analiz edilmiştir. Sabit modelde, GSYIHH için test istatistiği -2.601 , hidroelektrik enerji tüketimi için -2.513 , termik enerji tüketimi için -2.507 ve yenilenebilir enerji tüketimi için -2.541 olarak ve sabit+trendli modelde ise GSYIH için test istatistiği -3.190, hidroelektrik enerji tüketimi için -3.003, termik enerji tüketimi için -3.290 ve yenilenebilir enerji tüketimi için -3.017 olarak bulunmuştur. Ayrıca, bu iki modeldeki tüm değişkenler için ayrı ayrı olasılık değerleri hesaplanmıştır. Bulunan bu olasılık değerlerine $(\mathrm{p}>0.05)$ göre hem sabit hem de sabit+trendli modeldeki değişkenler için $\mathrm{H}_{0}$ hipotezleri kabul edilmiştir. Ek olarak, $\mathrm{I}(0)$ 'de tüm değişkenler için Cv5>t-bar olduğu görülmektedir. Böylece I(0) için $\alpha=0.05$ anlamlılık düzeyinde her iki modelde de değişkenlere ait zaman serilerinin durağan olmadığı yani serilerde birim kök varlığ 1 belirlenmiştir.

Verileri durağan hale getirmek amacıyla verilerin birinci farkları alınarak tekrardan serilerin durağanlığı sınanmıştır. Sabit modelde, GSYIH için test istatistiği -2.740 , hidroelektrik enerji tüketimi için -2.872 , termik enerji tüketimi için -2.732 ve yenilenebilir enerji tüketimi için -2.816 olarak ve sabit+trendli modelde ise GSYİH için test istatistiği -3.702 , hidroelektrik enerji tüketimi için -3.509 , termik enerji tüketimi için -3.487 ve yenilenebilir enerji tüketimi için -3.537 olarak bulunmuştur. Ayrıca, bu iki modeldeki tüm değişkenler için ayrı ayrı olasılık değerleri hesaplanmıştır. Bulunan bu olasılık değerlerine $(p<0.05)$ göre hem sabit hem de sabit+trendli modeldeki değişkenler için $\mathrm{H}_{0}$ hipotezleri reddedilmiştir. Ek olarak, I(1)'de tüm değişkenler için Cv5<t-bar olduğu görülmektedir. Böylece I(1) için $\alpha=0.05$ anlamll1ık düzeyinde her iki modelde de; GSYIH'a, hidroelektrik enerji tüketimine, termik enerji tüketimine ve yenilenebilir enerji tüketimine ait zaman serilerinin durağan olduğu veya bu serilerin birim kök içermediği kabul edilmektedir. 
Düzeyde durağan olmayan seriler durağan hale getirildikten sonra homojenlik durumu dikkate alınarak veri setine Westerlund (2007) panel eşbütünleşme testi uygulanmıştır. Tablo 4'te, GSYIH ile hidroelektrik, termik ve yenilenebilir enerji tüketimi arasında bir eşbütünleşme ilişkisi olup olmadığını belirlemek için eşbütünleşme test istatistikleri ve bunlara ait olasıllık değerleri verilmiştir.

Tablo 4

Eşbütünleşme test istatistik ve olasılık değerleri

\begin{tabular}{|c|c|c|c|c|c|c|}
\hline \multicolumn{2}{|c|}{ Değişkenler } & \multirow{2}{*}{$\frac{\text { İstatistik }}{\mathrm{Gt}}$} & \multirow{2}{*}{$\begin{array}{l}\text { Değer } \\
-3.718\end{array}$} & \multirow{2}{*}{$\begin{array}{r}\mathbf{Z} \text { değer } \\
-12.991\end{array}$} & \multirow{2}{*}{$\frac{\text { p değer }}{0.001}$} & \multirow{2}{*}{$\begin{array}{c}\begin{array}{c}\text { Bootstrap p } \\
\text { değer }\end{array} \\
0.010\end{array}$} \\
\hline \multirow{6}{*}{ 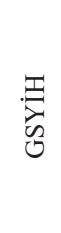 } & 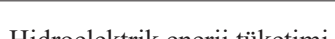 & & & & & \\
\hline & Hidroelektrik enerj1 tuketimı & $\mathrm{Ga}$ & -17.770 & -11.701 & 0.001 & 0.001 \\
\hline & \multirow{2}{*}{ Termik enerji tüketimi } & $\mathrm{Gt}$ & -3.875 & -14.048 & 0.001 & 0.001 \\
\hline & & $\mathrm{Ga}$ & -17.489 & -11.390 & 0.001 & 0.001 \\
\hline & \multirow{2}{*}{ Yenilenebilir enerji tüketimi } & $\mathrm{Pt}$ & -19.861 & -10.872 & 0.001 & 0.001 \\
\hline & & $\mathrm{Pa}$ & -12.348 & -10.451 & 0.001 & 0.001 \\
\hline
\end{tabular}

$(p<0.05)$, Bootstrap değerleri 1000 örneklem ile elde edilmiştir.

Eğim katsayıları heterojen olduğu için hidroelektrik ve termik enerji tüketimlerinin değerlendirilmesinde $G_{\alpha}$ ve $G_{\tau}$ istatistikleri, eğim katsayısı homojen olduğu için yenilenebilir enerji tüketiminin değerlendirilmesinde ise $P_{a}$ ve $P_{\tau}$ istatistikleri kullanılmıştır. Testlerin her biri için ayrı ayrı verilen bootstrap veya olasılık değerlerine $(p<0.05)$ göre $\mathrm{H}_{0}$ hipotezleri reddedilmiş ve böylece, GSYIH ile hidroelektrik enerji tüketimi, termik enerji tüketimi ve yenilenebilir enerji tüketimi değişkenleri arasında eşbütünleşmenin olduğu belirlenmiştir. Ayrıca, değişkenler arasında eşbütünleşme olması nedeniyle uzun dönemli ilişki incelenmiştir.

Uzun dönem eşbütünleşme katsayılarını tahmin etmek ve ilişkinin yönünü belirlemek için Pesaran (2007) testi uygulanmış ve sonuçlar Tablo 5'de verilmiştir.

Tablo 5

Pesaran CCE (2007) test istatistik sonuçları

\begin{tabular}{lcccccc}
\hline \multirow{2}{*}{ GSYIH } & Katsayı & $\begin{array}{c}\text { Standart } \\
\text { Hata }\end{array}$ & $\mathbf{Z}$ değeri & $\mathbf{p}<|\mathbf{Z}|$ & \multicolumn{2}{c}{ \%95 Güven Aralığı } \\
\cline { 5 - 7 } & & & & Alt GS & Üst GS \\
\hline Hidroelektrik enerji tüketimi & 1.825144 & 1.7510 & 1.04 & 0.297 & -1.606 & 5.257 \\
Termik enerji tüketimi & -0.465102 & 0.4449 & -1.05 & 0.296 & 1.337 & 4.069 \\
Yenilenebilir enerji tüketimi & 0.529379 & 0.7510 & 1.01 & 0.296 & -1.782 & 4.321 \\
\hline
\end{tabular}

Tablo 5 incelendiğinde, GSYİH ile hidroelektrik enerji tüketimi arasında uzun dönemli pozitif yönlü bir ilişkinin olduğu görülmektedir. Hidroelektrik enerji tüketiminde meydana gelecek bir birimlik artış GSYIH'da $1.825^{\prime}$ lik bir artış meydana getirmektedir. Ayrıca, hidroelektrik enerji tüketiminin verilen türevlerine göre GSYİH'ye en yüksek katkı yapan enerji türü olduğu belirlenmiştir. Bu durum uzun dönemde hidroelektrik enerji üretim maliyetinin verilen diğer iki türe göre daha düşük olmasına bağlanabilir. 
GSYİH ile termik enerji tüketimi arasında uzun dönemli negatif yönlü bir ilişkinin olduğu görülmektedir. Termik enerji tüketiminde meydana gelecek bir birimlik artış GSYİH'da $0.465^{\prime}$ 'lik bir düşüş meydana getirmektedir. Termik enerji üretim maliyetinin yüksek olması bu negatif etkinin sebepleri arasında gösterilebilir. Zira bu üretim merkezlerinin üretim yapabilmesi için yeraltı enerji kaynakları (petrol, kömür, doğalgaz, vb.) gibi başka bir enerji kaynağına ihtiyaç duymaktadır. Ancak OECD ülkelerinin birçoğu bu ihtiyaçlarını ithal ederek gidermektedir. Bu durum ekonomik büyüme üzerinde negatif bir etki göstermektedir.

GSYİH ile yenilenebilir enerji tüketimi arasında uzun dönemli pozitif yönlü bir ilişkinin olduğu görülmektedir. Yenilenebilir enerji tüketiminde meydana gelecek bir birimlik artış GSYİH'da 0.529'luk bir artış meydana getirmektedir. Uzun dönemde GSYİH'ya etkisi termik enerji tüketiminden yüksek olmasına rağmen hidroelektrik enerji tüketiminden düşüktür. Ancak yine de son dönemlerde yenilenebilir enerji tüketimi bakımından, birçok dünya ülkesinde ilerleme görülmektedir. Bunun en temel sebepleri arasında çevreye verilen zararın diğer enerji üretim türlerine göre minimum olması ve enerji bakımında dışa bağımlılığın düşürülmeye çalışılması gösterilebilir.

\section{Tartışma ve Sonuç}

Enerji tüketimi her geçen gün büyük oranda artış göstermektedir. Gerek nüfus artış1 gerek sanayileşme bu tüketimi artıran en önemli sebepler arasında yer almaktadır. Rekabet dünyasında yer edinebilmek için ülkelerin özellikle sanayi ve teknoloji alanında üretici olmaları ve bu alanda dışa bağımlı olmamaları için enerjiye büyük ihtiyaç duymaktadırlar. Tüketilen enerji miktarı bir açıdan da ülkenin üretim gücünü göstermektedir. Üretim alanında güçlü olan ülkeler aynı zamanda güçlü bir ekonomiye sahiptirler. Bu durum, enerjinin ekonomik büyüme üzerinde etkisinin pozitif yönde olduğunun bir göstergesidir. Bilimsel çalışmaların çoğu bu durumu desteklemektedir.

Literatürde ekonomik büyüme ve enerji tüketimi arasındaki ilişki üzerini birçok çalışma bulunmakta ve bu çalışmalardan bazıları literatür karşılaştırılması için verilmiştir. Erbaykal (2007), gelişmekte olan bazı ülkelerin üretim göstergelerine enerji göstergesini de ekleyerek ekonomik kalkınma bakımından enerji faktörünü incelemeyi amaçlamıştır. Sonuç olarak enerjinin diğer üretim göstergelerinden daha fazla ekonomik büyümeyi etkilediğini belirtmiştir. Karagöl, Erbaykal ve Ertuğrul (2007), küreselleşmenin artmasıyla enerjinin ekonomik büyümede önemli bir girdi olduğunu belirtmiştir. Ayrıca, üretimde enerji kullanımının artmasıyla birlikte enerji ihtiyacı önemli bir sorun oluşturduğunu, böylece ülkelerin farklı alternatif enerji kaynakları arayışlarına girdiğini ifade etmiştir. Apergis ve Payne (2010), OECD ülkelerinde ekonomik büyüme göstergeleri ve yenilenebilir enerji tüketimi arasındaki ilişki panel veri analizi ile incelenmiştir. GSYİH ile yenilenebilir enerji tüketimi arasında uzun dönemde pozitif yönlü ve anlamlı bir ilişki bulunmuştur. Naseri, 
Motamedi ve Ahmadian. (2016), OECD ülkelerinin 1990-2012 yıllarını kapsayan yenilenebilir enerji tüketimi ile ekonomik büyüme arsındaki ilişkiyi araştırmıştır. Çalışmada, yenilenebilir enerji tüketimindeki artışın ekonomik büyümede de artışa yol açtığı sonucuna ulaşmışlardır. Gövdeli (2018), OECD ve OECD dışı ülkelerde farklı enerji kaynakları ile ekonomik büyüme arasındaki ilişkiyi araştırmıştır. Eşbütünleşme test sonuçlarına göre enerji tüketimi ile ekonomik büyüme arasında uzun dönem eşbütünleşmenin ilişkisinin olduğu ve ilişkinin anlamlı ve pozitif yönde olduğu belirlenmiştir. Yorulmaz (2019), 33 OECD ülkesinin 1995-2015 yıllarına ait enerji tüketimi ve ekonomik büyüme verileri kullanılarak bunlar arasındaki ilişki panel veri analizi ile incelenmiştir. Eşbtünleşme test sonucunda, ekonomik büyüme ve enerji tüketimi arasındaki ilişki uzun vadede anlamlı bulunmuş ve bu iki değişkenin birbirinden etkilendiği ifade edilmiştir. Böylece, yapılan çalışma ile literatürdeki çalışmalar asında iyi bir uyumun olduğu ve genel anlamda literatürdeki çalışmalar ile benzerlik gösterdiği söylenebilir. Çalışma, literatürde yer alan çalışmalardan enerji tüketimlerine ait güncel veriler bakımından farklılık göstermektedir. Ayrıca, literatürde incelenen çalışmaların bazılarından değişken sayısı ve türü bazılarından ise ülke veya yöntem bakımından farklı olduğu düşünülmektedir.

Bu çalışmada, enerji üretim kaynaklarına göre kilovatsaat (kwh) cinsinden tüketilen elektrik enerjinin toplam tüketim içerisindeki yıllık tüketim oranı ile ekonomik büyüme arasında bir ilişki olduğu panel eşbütünleşme testi ile belirlenmiş̧ir. Sonuçlara göre hidroelektrik ve yenilenebilir enerji tüketiminin ekonomiyi uzun dönemde pozitif yönde etkilediği gözlenmiştir. Ancak, üretim maliyetlerinin sebep olduğu olumsuzluklar nedeniyle termik enerji tüketiminin ekonomiyi uzun dönemde negatif yönde etkilediği sonucuna varılmıştır.

Çalışmada kullanılan enerji türlerine ait tüketimlerin ekonomi üzerindeki etkisi açıklanmıştır. Özellikle Türkiye gibi gelişmekte olan ve yeraltı enerji kaynaklanı yetersiz olan ülkeler kendi enerji ihtiyaçlarını gidermek için dışa bağımlılıklarını düşürerek ekonomik gelişim açısından büyük bir kazanç elde edeceklerdir. Bunun için yenilenebilir enerji kaynakları gibi farklı alternatif enerji kaynaklarına yönelerek ve bu alanda yatırımlar yaparak gelişim açısından önemli ilerleme sağlayabilirler. Aynı zamanda küresel ısınma ile ekolojik denge de meydana gelen bozulmaları azaltmak amacıyla doğaya daha az zarar veren yenilenebilir enerji tüketimine yönelmek dünya için büyük önem arz etmektedir.

Hakem Değerlendirmesi: Dış bağımsız.

Çıkar Çatışması: Yazarlar çıkar çatışması bildirmemiştir.

Finansal Destek: Yazarlar bu çalışma için finansal destek almadığını beyan etmiştir.

Peer-review: Externally peer-reviewed.

Conflict of Interest: The authors has no conflict of interest to declare.

Grant Support: The authors declared that this study has received no financial support. 


\section{Kaynakça/References}

Ağaçbiçer, G. (2010). Yenilenebilir Enerji Kaynaklarının Türkiye Ekonomisine Katkısı ve Yapılan Swot Analizler (Yüksek Lisans Tezi). Çanakkale Onsekiz Mart Üniversitesi Sosyal Bilimler Enstitüsü, Çanakkale.

Altunkaynak, B. (2007). Sektörel panel veri analizi yaklaşımıyla Türkiye'nin AB ülkelerine imalat sanayi bakımından ihracatının belirlenmesi (Doktora Tezi). Gazi Üniversitesi Fen Bilimleri Enstitüsü, Ankara.

Apergis, N., \& Payne, J. (2010). Renewable Energy Consumption and Economic Growth: Evidence From A Panel of OECD Countries. Energy Policy, 38(1), 656-660.

Aytun, C. ve Akın, C. S. (2014). OECD Ülkelerinde Telekomünikasyon Altyapısı ve Ekonomik Büyüme: Yatay Kesit Bağımlı Heterojen Panel Nedensellik Analizi. İktisat Iş̧letme ve Finans, 29(340), 69-94.

Baltagi, B. H. (2005). Econometric Analysis of Panel Data (3. Bask1). England: West Sussex John Wiley and Sons, Ltd.

Banerjee, A., Dolado, J., \& Mestre, R. (1998). Error-correction Mechanism Tests for Cointegration in a Single-equation Framework. Journal of Time Series Analysis, 19(3), 267-283.

Croissant, Y., \& Millo, G. (2019). Panel Data Econometrics with $R$ (1 Bask1). England: West Sussex John Wiley and Sons, Ltd.

Das, P. (2019). Econometrics in Theory and Practive. Singapore: Springer Nature Singapore Pte Ltd. Gateway East.

Dickey, D. A., \& Fuller, W. A. (1979). Distribution of the Estimators for Autoregressive Time Series with a Unit Root. Journal of the American Statistical Association, 427-431.

Enders, W. (2004). Applied Econometrics Time Series. New York: Wiley.

Erataş, F. ve Başçı Nur, H. (2013). Dış Borç ve Ekonomik Büyüme İlişkisi: "Yükselen Piyasa Ekonomileri” Örneği. Marmara Üniversitesi İ.I.B. Dergisi, 35(2), 207-23.

Erbaykal, E. (2007). Türkiye'de Enerji Tüketiminin Ekonomik Büyüme Üzerindeki Etkisi. Beykent Üniversitesi Sosyal Bilimler Dergisi, 1 (1), 29- 44.

Efron, B., \& Tibshirani, R. ( 1993). An Introduction to the Bootstrap. London Chapman \& Hall/Crc.

Ertuğrul, H. M. (2011). Türkiye'de Elektrik Tüketimi Büyüme İlişkisi: Dinamik Analiz. Enerji, Piyasa ve Düzenleme, 2, 49-73.

Eygü, H. (2018). Enflasyon, İşsizlik ve Dış Ticaret Arasındaki İlişkinin İncelenmesi: Türkiye Örneği (1990-2017). Kastamonu University Journal of Economics \& Administrative Sciences Faculty, 20(2).

Göral, F. (2015). Doğal Gaz Fiyatlarını Etkileyen Faktörler: Panel Veri Analizi (Doktora Tezi). Hacettepe Üniversitesi Sosyal Bilimleri Enstitüsü. Ankara.

Gövdeli, T. (2018). Enerji Tüketimi ile Ekonomik Büyüme Arasındaki Illişki: Panel Veri Analizi (Doktora Tezi). Gaziantep Üniversitesi Sosyal Bilimleri Enstitüsü. Gaziantep.

Gujarati, D. N. (2003). Basic Econometrics. New York: The McGraw-Hill Companies, Inc.

Hsiao, C. (2014). Analysis of Panel Data (3. Bask1). New York: Cambridge University Press.

IBRD IDA. (2020). The World Bank, https://databank.worldbank.org/source/world-developmentindicators (Erişim Tarihi: 10.02.2020) 
İşleyen, Ş. (2019). Tarım Ve Sanayi Sektöründe İstihdamın Ekonomik Büyüme Üzerindeki Etkisi: Bazı Oecd Ülkeleri Örneği (1993-2017). Journal of Economics, Finance and Accounting (JEFA), 6(2), 102-114.

İşleyen, Ş., Altun, Y. ve Görür, Ç. (2017). The Causalıty Relatıonshıp Between Interest Rate And Income With Investment In Usa: 1965-2016, Akademik Sosyal Araştırmalar Dergisi, 5(60), 146-163.

Karagöl, E., Erbaykal, E. ve Ertuğrul, H. M. (2007). Türkiye'de Ekonomik Büyüme İle Elektrik Tüketimi İlişkisi: Sınır Testi Yaklaşımı. Doğuş Üniversitesi Dergisi, 8(1), 72-80.

Karakaş, E., ve Balcı İzgi, B. (2018). Yenilenebilir Enerji Kaynakları Ve Ekonomik Büyüme İlişkisinin Ampirik Analizi. OECD Örneği. Kent Akademisi, Kent kültürü ve Yönetimi Hakemli Elektronik Dergi, 11(1), 99-107.

Menyah, K., Nazlığlu, Ş. ve Wolde-Rufael, Y. (2014). Financial Development, Trade Openness and Economic Growth in African Countries: New Insights from a Panel Causality Approach. Economic Modelling, 37, 386-394.

Naseri, S. F., Motamedi, S. \& Ahmadian M. (2016). Study of Mediated Consumption Effect of Renewable Energyon Economic Growth of OECD Countries. Procedia Economics And Finance, 36 (2016) 502509.

Özşahin, Ş., Mucuk, M., ve Gerçeker, M. (2016). Yenilenebilir Enerji ve Ekonomik Büyüme Arasındaki İlişki: BRICS-T Ülkeleri Üzerine Panel ARDL Analizi. Siyaset, Ekonomi ve Yönetim Araştırmaları Dergisi, 4 (4), 111-130.

Pedroni, P. (2004). Panel Cointegration: Asymptotic and Finite Sample Properties of Pooled Time Series Tests with an Application to the PPP Hypothesis. Econometric Theory, 20(3), 597-625.

Pesaran, M. H. (2004). General Diagnostic Tests for Cross Section Dependence in Panels. Working Paper No:0435, University of Cambridge.

Pesaran, M. H. (2007). A simple panel unit root test in the presence of crosssection dependence. Journal of Applied Econometrics, 22(2), 265-312.

Pesaran, M. H. (2015). Time Series and Panel Data Econometrics (1. Bask1), Oxford: Oxford University Press.

Sevüktekin, M. ve Nargeleçekenler, M. (2005). Ekonometrik Zaman Serileri Analizi. Ankara: Nobel Yayınları.

Shao, J. ve Tu D. (1995). The jackknife and the bootstrap. New York: Springer-Verlag.

Stata: Software for Statistics and Data Science, Stata15 for windows version

Westerlund, J. (2007). Testing for error correction in panel data. Oxford Bulletin of Economics and statistics, 69(6), 709-748.

Wooldridge, J. M. (2002). Econometric analysis of cross section and panel data. London: The MIT Press.

Yerdelen Tatoğlu, F. (2013). Panel Veri Ekonometrisi (2.Bask1). İstanbul: Beta

Yerdelen Tatoğlu, F. (2017). Panel Zaman Serileri Analizi: Stata Uygulamalı (2.Bask1). İstanbul: Beta.

Yorulmaz, H. (2019). Enerji Tüketimi ve Ekonomik Büyüme İlişkisi Üzerine Bir Panel Veri Analizi (Yüksek Lisans Tezi). Tekirdağ Namık Kemal Üniversitesi Sosyal Bilimleri Enstitüsü, Tekirdağ. 
